Article

\title{
Four New Citrinin Derivatives from a Marine-Derived Penicillium sp. Fungal Strain
}

\author{
Mei Ling Wang ${ }^{1}$, Chun Hua Lu ${ }^{2}$, Qing Yan Xu ${ }^{1}$, Si Yang Song ${ }^{1}$, Zhi Yu Hu ${ }^{1}$ and \\ Zhong Hui Zheng ${ }^{1, *}$
}

1 School of Life Sciences, Xiamen University, 422 South Siming Road, Xiamen, Fujian 361005, China; E-Mails: wml1211@126.com (M.L.W); xuqingyan@xmu.edu.cn (Q.Y.X); sysong@xmu.edu.cn (S.Y.S); huzhiyu@xmu.edu.cn (Z.Y.H)

2 Key Laboratory of Chemical Biology (Ministry of Education), School of Pharmaceutical Sciences, Shandong University, Jinan, Shandong 250012, China; E-Mail: ahua0966@sdu.edu.cn

* Author to whom correspondence should be addressed; E-Mail: zhzheng@xmu.edu.cn; Tel./Fax: +86-592-2181722.

Received: 11 April 2013; in revised form: 9 May 2013 / Accepted: 10 May 2013 / Published: 16 May 2013

\begin{abstract}
Four new citrinin derivatives, including two citrinin dimers and two citrinin monomer derivatives, were isolated and identified from a marine-derived fungal strain Penicillium sp. ML226 along with six known related compounds. Their structures were elucidated by spectroscopic and chemical methods. The new compounds showed modest cytotoxic activity against HepG-2 cell line and weak antimicrobial activity against Staphylococcus aureus.
\end{abstract}

Keywords: citrinin; Penicillium sp. ML226; new metabolites; marine fungus

\section{Introduction}

The search for new bioactive natural products is still the main way of discovering new drugs. Investigating the secondary metabolites of microorganisms isolated from specific ecological environments may increase the chance of finding compounds with novel skeletons and varied and unique bioactivities. It was reported that the specific situations that microorganisms live in might activate some silent genes and induce some unique biosynthetic pathways [1]. Marine microorganisms have attracted extensive attention in this context. Marine fungi are an important resource to find 
chemically and biologically diverse compounds due to their special living environment $[2,3]$. In order to search for new bioactive natural products, a marine-derived fungal strain, ML226, authenticated as Penicillium sp., was isolated from the Taiwan Strait, China. The EtOAc extract of Penicillium sp. ML226 exhibited cytotoxic and antimicrobial activity. Chemical investigation of the EtOAc extract of Penicillium sp. ML226 led to the isolation of two new citrinin dimers-penicitrinone E (1) and penicitrinol $\mathrm{J}(\mathbf{2})$ - two new citrinin monomer derivatives - penicitrinol K (3) and citrinolactone D (4) - together with six known compounds-penicitrinone A [4] (5), penicitrinone B [4] (6), citrinolactone B [5] (7), citrinin [6] (8), 2,3,4-trimethyl-5,7-dihydroxy-2,3-dihydrobenzofuran [7] (9) and phenol A [8] (10) (Figure 1). In this paper, we report the isolation and structural elucidation of compounds 1-10 and the cytotoxic and antimicrobial activity of 1-4. They all showed weak cytotoxicity against HepG-2 cell line in the concentration of $10 \mu \mathrm{g} / \mathrm{mL}$ with inhibition rate from $6 \%$ to 30\%. Compounds $\mathbf{2}$ and $\mathbf{3}$ showed weak antimicrobial activity against Staphylococcus aureus.

Figure 1. Structures of the isolated compounds 1-10.

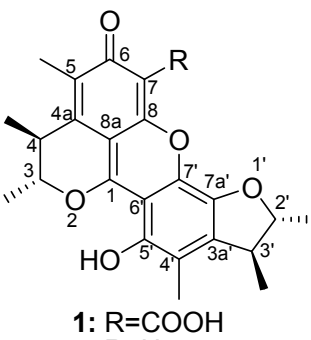

5: $\mathrm{R}=\mathrm{H}$

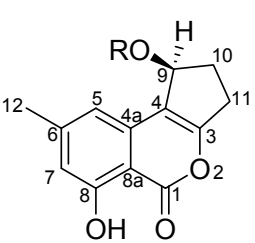

4: $\mathrm{R}=\mathrm{CH}_{3}$ 7: $\mathrm{R}=\mathrm{H}$

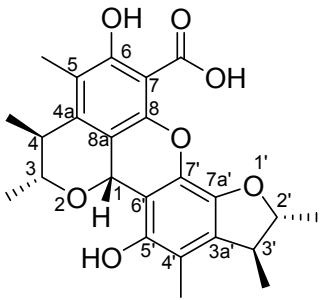

2

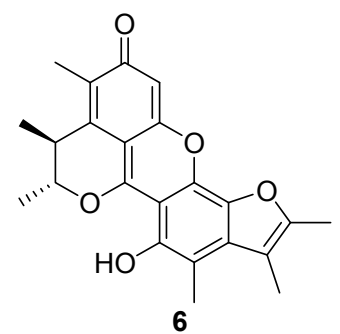

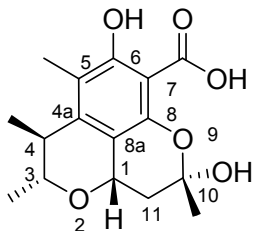<smiles>CC1=C2C(=CO[C@@H](C)[C@@H]2C)C(O)=C(C(=O)O)C1=O</smiles><smiles>Cc1c(O)cc(O)c2c1[C@H](C)[C@H](C)O2</smiles><smiles>C[C@@H](O)[C@H](C)c1cc(O)cc(O)c1[13CH3]</smiles>

\section{Results and Discussion}

\subsection{Structural Elucidation of Compounds}

Penicitrinone E (1) was obtained as a red, amorphous powder. $[\alpha]_{D}^{25} 0(0.002, \mathrm{MeOH})$. A molecular formula of $\mathrm{C}_{24} \mathrm{H}_{24} \mathrm{O}_{7}$ was assigned based on the interpretation of HRESIMS data at $\mathrm{m} / z$ 425.15965 $[\mathrm{M}+\mathrm{H}]^{+}$(calcd. 425.1600). The ${ }^{1} \mathrm{H}-\mathrm{NMR}$ data of $\mathbf{1}$ showed four tertiary methyl signals, two aromatic methyl signals, four $\mathrm{sp}^{3}$ methine protons (two oxygenated), and one hydroxyl proton (Table 1). The ${ }^{13} \mathrm{C}-\mathrm{NMR}$ and DEPT spectra for 1 displayed 24 carbon signals comprising four tertiary methyls, two aromatic methyls, four $\mathrm{sp}^{3}$ methines (two oxygenated), two carbonyl carbons, and $12 \mathrm{sp}^{2}$ quaternary 
carbons (Table 1). Except for those of the benzopyran moiety, the NMR data were quite similar to those of 5 [4], indicating that they shared the same molecular skeleton. Compared with those of $\mathbf{5}$, the NMR spectra of 1 exhibited an additional carboxyl group $\left(\delta_{c} 165.4\right)$, two downfield shifts effect of C-1 $(+4.6 \mathrm{ppm})$ and $\mathrm{C}-8(+2.7 \mathrm{ppm})$ because of the inductive effect of the additional carboxyl group. The $\mathrm{C}-7$ of $\mathbf{5}$ is a $\mathrm{sp}^{2}$ methine carbon but the $\mathrm{C}-7$ of $\mathbf{1}$ is a $\mathrm{sp}^{2}$ quaternary carbon, indicating that the carboxyl group was linked to C-7.

Table 1. ${ }^{1} \mathrm{H}$ - and ${ }^{13} \mathrm{C}-\mathrm{NMR}(600$ and $150 \mathrm{MHz})$ data for compounds $\mathbf{1}$ and $\mathbf{2}\left(\mathrm{CDCl}_{3}, \delta\right.$ in ppm).

\begin{tabular}{|c|c|c|c|c|}
\hline \multirow{2}{*}{ No. } & \multicolumn{2}{|l|}{1} & \multicolumn{2}{|l|}{2} \\
\hline & $\delta_{H}$ (mult., $J[H z]$, int.) & $\delta_{c}$ & $\delta_{H}$ (mult., $J[\mathrm{~Hz}]$, int.) & $\delta_{c}$ \\
\hline 1 & - & $161.1 \mathrm{~s}$ & $5.71(\mathrm{~s})$ & $66.3 d$ \\
\hline 3 & $5.17(q, 6.7)$ & $83.2 \mathrm{~d}$ & $4.10(\mathrm{dq}, 6.1,6.8)$ & $79.0 \mathrm{~d}$ \\
\hline $3-\mathrm{CH}_{3}$ & $1.49(\mathrm{~d}, 6.7,3 \mathrm{H})$ & $19.04 \mathrm{q}$ & $1.47(\mathrm{~d}, 6.8,3 \mathrm{H})$ & $21.9 \mathrm{q}$ \\
\hline 4 & $3.29(\mathrm{q}, 7.2)$ & $34.8 \mathrm{~d}$ & $3.03(\mathrm{dq}, 6.1,7.0)$ & $37.7 \mathrm{~d}$ \\
\hline $4-\mathrm{CH}_{3}$ & $1.38(\mathrm{~d}, 7.2,3 \mathrm{H})$ & $18.97 \mathrm{q}$ & $1.34(\mathrm{~d}, 7.0,3 \mathrm{H})$ & $19.6 \mathrm{q}$ \\
\hline $4 a$ & - & $132.7 \mathrm{~s}$ & - & $144.7 \mathrm{~s}$ \\
\hline 5 & - & $130.8 \mathrm{~s}$ & - & $120.6 \mathrm{~s}$ \\
\hline $5-\mathrm{CH}_{3}$ & $2.22(\mathrm{~s}, 3 \mathrm{H})$ & $10.9 q$ & $2.21(\mathrm{~s}, 3 \mathrm{H})$ & $11.2 \mathrm{q}$ \\
\hline 6 & - & $183.8 \mathrm{~s}$ & - & $161.9 \mathrm{~s}$ \\
\hline $6-\mathrm{OH}$ & - & - & $12.52(\mathrm{~s})$ & - \\
\hline 7 & - & $103.1 \mathrm{~s}$ & - & $98.0 \mathrm{~s}$ \\
\hline 7-COOH & - & $165.4 \mathrm{~s}$ & - & $170.6 \mathrm{~s}$ \\
\hline 8 & - & $160.9 \mathrm{~s}$ & - & $145.3 \mathrm{~s}$ \\
\hline $8 \mathrm{a}$ & - & $99.5 \mathrm{~s}$ & - & $108.9 \mathrm{~s}$ \\
\hline $2^{\prime}$ & $4.77(\mathrm{dq}, 4.3,6.4)$ & $88.4 \mathrm{~d}$ & $4.56(\mathrm{~m})$ & $88.3 \mathrm{~d}$ \\
\hline $2^{\prime}-\mathrm{CH} 3$ & $1.47(\mathrm{~d}, 6.4,3 \mathrm{H})$ & $21.0 \mathrm{q}$ & $1.36(\mathrm{~d}, 6.5,3 \mathrm{H})$ & $20.9 q$ \\
\hline $3^{\prime}$ & $3.25(\mathrm{dq}, 4.3,7.1)$ & $45.0 \mathrm{~d}$ & $3.09(\mathrm{~m})$ & $44.3 \mathrm{~d}$ \\
\hline 3'-CH3 & $1.36(\mathrm{~d}, 7.1,3 \mathrm{H})$ & $18.82 q$ & $1.35(\mathrm{~d}, 7.2,3 \mathrm{H})$ & $19.3 q$ \\
\hline $3 \mathrm{a}^{\prime}$ & - & $142.4 \mathrm{~s}$ & - & $133.0 \mathrm{~s}$ \\
\hline $4^{\prime}$ & - & $118.2 \mathrm{~s}$ & - & $117.8 \mathrm{~s}$ \\
\hline $4^{\prime}-\mathrm{CH} 3$ & $2.28(\mathrm{~s}, 3 \mathrm{H})$ & $11.6 \mathrm{q}$ & $2.18(\mathrm{~s}, 3 \mathrm{H})$ & $11.6 \mathrm{q}$ \\
\hline $5^{\prime}$ & - & $147.2 \mathrm{~s}$ & - & $147.5 \mathrm{~s}$ \\
\hline $5^{\prime}-\mathrm{OH}$ & $8.25(\mathrm{~s})$ & - & $7.92(\mathrm{~s})$ & - \\
\hline $6^{\prime}$ & - & $102.2 \mathrm{~s}$ & - & $105.3 \mathrm{~s}$ \\
\hline $7^{\prime}$ & - & $136.2 \mathrm{~s}$ & - & $130.7 \mathrm{~s}$ \\
\hline $7 a^{\prime}$ & - & $139.2 \mathrm{~s}$ & - & $138.1 \mathrm{~s}$ \\
\hline
\end{tabular}

${ }^{\mathrm{a}}$ The assignments were based on DEPT, ${ }^{1} \mathrm{H}-{ }^{1} \mathrm{H}$ COSY, HMQC, and HMBC experiments, and chemical shift values are in ppm relative to TMS. “-”: no signal.

This deduction was further supported by analyses of the 2D (HMQC, ${ }^{1} \mathrm{H}-{ }^{1} \mathrm{H}$ COSY and HMBC) NMR spectra (Figure 2). The relative configuration of the two methyl residues in the benzopyran moiety was determined as trans based on the NOESY correlation of $4-\mathrm{CH}_{3}$ with $3-\mathrm{H}$ and $J^{3,4}$ $(<0.5 \mathrm{~Hz})$; and the relative configuration of the two methyl residues in the benzofuran moiety was determined as trans based on the NOESY correlation of $3^{\prime}-\mathrm{CH}_{3}$ with $2^{\prime}-\mathrm{H}$ and $J^{2^{\prime}, 3^{\prime}}(=4.3 \mathrm{~Hz}$ ) (Figure 3 ). 
Figure 2. ${ }^{1} \mathrm{H}-{ }^{1} \mathrm{H}$ COSY and key HMBC correlations of compounds $\mathbf{1}-\mathbf{4}$.

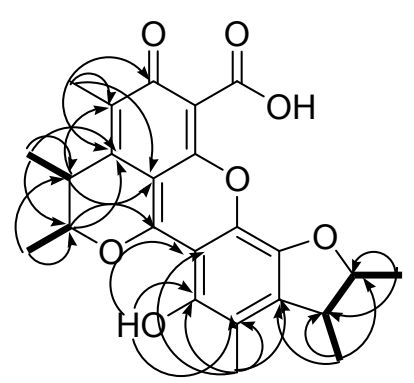

1

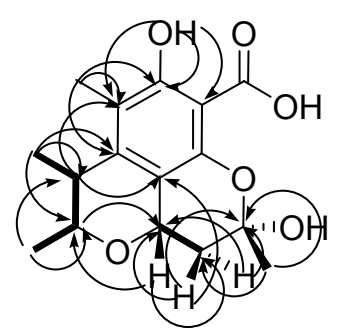

3

HMBC

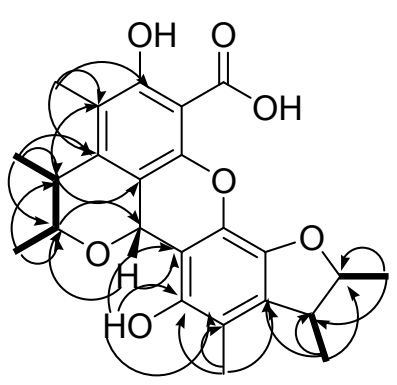

2

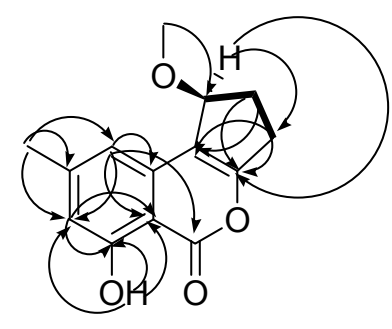

4

${ }^{1} \mathrm{H}-{ }^{1} \mathrm{H}$ COSY

Figure 3. Key NOESY effects of compounds 1-3.
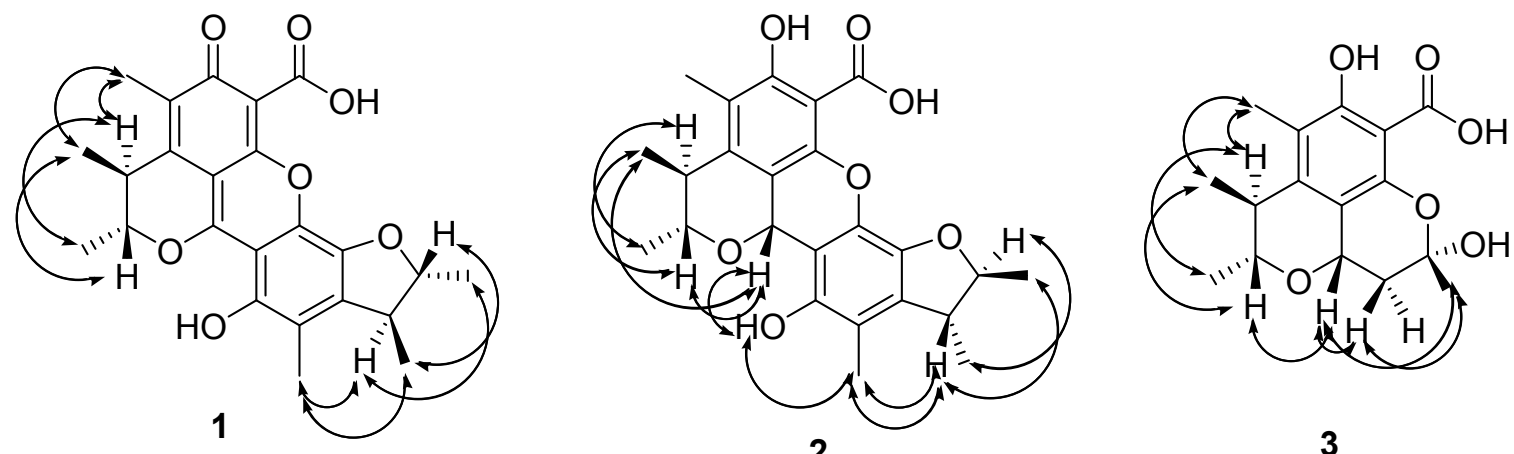

Penicitrinol J (2) was isolated as a pale yellow, amorphous powder. $[\alpha]_{D}^{25}-30.0(0.001, \mathrm{MeOH})$. The molecular formula of 2 was determined as $\mathrm{C}_{24} \mathrm{H}_{26} \mathrm{O}_{7}$ by HRESIMS at $m / z 427.17601[\mathrm{M}+\mathrm{H}]^{+}$(calcd. 427.1757). The ${ }^{1} \mathrm{H}-\mathrm{NMR}$ data of 2 showed four tertiary methyl signals, two aromatic methyl signals, five $\mathrm{sp}^{3}$ methine protons (three oxygenated), and two hydroxyl protons (Table 1). The ${ }^{13} \mathrm{C}-\mathrm{NMR}$ and DEPT spectra for $\mathbf{2}$ displayed 24 carbon signals including four tertiary methyls, two aromatic methyls, five $\mathrm{sp}^{3}$ methines (three oxygenated), one carbonyl carbon, and $12 \mathrm{sp}^{2}$ quaternary carbons (Table 1). The NMR data were quite similar to those of $\mathbf{1}$ except for those of the benzopyran moiety. Compared with those of $\mathbf{1}$, the NMR spectra of $\mathbf{2}$ exhibited an additional oxygenated $\mathrm{sp}^{3}$ methine proton $\left(\delta_{H} 5.71\right)$ and an additional oxygenated $\mathrm{sp}^{3}$ methine carbon $\left(\delta_{c} 66.3\right)$, but missed one carbonyl carbon $\left(\delta_{c} 183.8\right.$ in 1). These indicated one of the two additional protons was linked to $\mathrm{C}-1$, the other was the hydroxyl proton of 6-OH, which was further supported by the downfield shift effect of C-4a (+12 ppm) and the highfield shifts effect of $\mathrm{H}-3(-1.07 \mathrm{ppm})$ and $\mathrm{H}-4(-0.26 \mathrm{ppm})$ as a result of the missing of the double 
bond between C-1 and C-8a, and the 2D (HMQC, ${ }^{1} \mathrm{H}-{ }^{1} \mathrm{H}$ COSY and HMBC) NMR spectra (Figure 2). The NOESY correlation of $3-\mathrm{H}$ with $4-\mathrm{CH}_{3}$ and $J^{3,4}(=6.1 \mathrm{~Hz})$ established the trans of the two methyl residues in the benzopyran moiety; The NOESY correlation of $2^{\prime}-\mathrm{H}$ with $3^{\prime}-\mathrm{CH}_{3}$ and $J^{2,3}(<0.5 \mathrm{~Hz})$ demonstrated the trans of the two methyl residues in the benzofuran moiety; and the relative configuration of the 1-H and 3-H was determined as cis based on the NOESY correlations of 1-H with 3-H, 5'-OH and $4-\mathrm{CH}_{3}$ (Figure 3).

Penicitrinol K (3) was isolated as a white, amorphous powder. $[\alpha]_{D}^{25}-125.2(0.002, \mathrm{MeOH})$. The benzopyran moiety's molecular formula of 3 was determined as $\mathrm{C}_{13} \mathrm{H}_{14} \mathrm{O}_{5}$ by HRESIMS at $\mathrm{m} / \mathrm{z}$ 273.07299 [M + Na $]^{+}$(calcd. 273.0739) (Figure 4).

Figure 4. The benzopyran moiety of compound 3.<smiles>Cc1c(O)c(C(=O)O)c2c3c1[C@@H](C)[C@H](C)O[C@H]3C[C@](C)(O)O2</smiles>

3

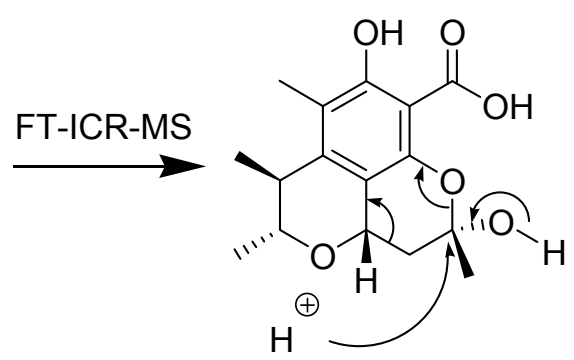<smiles>CC1=C(O)C(C(=O)O)C(=O)C2=CO[C@H](C)[C@H](C)C21</smiles>

benzopyran moiety

The molecular formula of 3 was determined to be $\mathrm{C}_{16} \mathrm{H}_{20} \mathrm{O}_{6}$ by ESI-MS at $m / z 331.2[\mathrm{M}+\mathrm{Na}]^{+}$and $291.4\left[\mathrm{M}-\mathrm{H}_{2} \mathrm{O}+\mathrm{H}\right]^{+}$. The ${ }^{1} \mathrm{H}-\mathrm{NMR}$ data of $\mathbf{3}$ showed three tertiary methyl signals, one aromatic methyl signal, one $\mathrm{sp}^{3}$ methylene signal, three $\mathrm{sp}^{3}$ methine protons (two being oxygenated), and one hydroxyl proton (Table 2). The ${ }^{13} \mathrm{C}-\mathrm{NMR}$ and DEPT spectra of $\mathbf{3}$ displayed signals for three tertiary methyls, one aromatic methyl, one $\mathrm{sp}^{3}$ methylene, three $\mathrm{sp}^{3}$ methines (two being oxygenated) and eight quaternary carbons (Table 2). Compared to those of $\mathbf{2}$, compound $\mathbf{3}$ shared the same benzopyran moiety with 2 which was further supported by the $2 \mathrm{D}$ (HMQC, ${ }^{1} \mathrm{H}-{ }^{1} \mathrm{H}$ COSY and HMBC) spectra (Figure 2), and the NMR spectra of 3 exhibited a high-field shift effect of $\mathrm{C}-1(-1.01 \mathrm{ppm})$. The ${ }^{1} \mathrm{H}-{ }^{1} \mathrm{H}$ COSY correlations between 1-H and 11- Ha, 1-H and 11- Hb, and key HMBC correlations from 1-H, $11-\mathrm{H}$ and $10-\mathrm{CH}_{3}$ to corresponding carbons indicated that $\mathrm{C}-11$ was linked to $\mathrm{C}-1, \mathrm{C}-10$ was linked to $\mathrm{C}-11$, and $10-\mathrm{CH}_{3}$ was linked to $\mathrm{C}-10$ (Figure 2). Finally $\mathrm{C}-10$ was linked to $\mathrm{C}-8$ via $\mathrm{O}$ and $10-\mathrm{OH}$ was linked to C-10, which established by the molecular formula of 3. The NOESY correlation of 3-H with $4-\mathrm{CH}_{3}$ and $J^{3,4}(=6.3 \mathrm{~Hz})$ determined the trans of $3-\mathrm{CH}_{3}$ and $4-\mathrm{CH}_{3}$. The NOESY correlations between $1-\mathrm{H}$ and $3-\mathrm{H}$ and $1-\mathrm{H}$ and $10-\mathrm{CH}_{3}$ established the cis configurations of $1-\mathrm{H}$ and $3-\mathrm{H}$ and $1-\mathrm{H}$ and $10-\mathrm{CH}_{3}$ (Figure 3).

Table 2. The NMR data for compound $3\left(\mathrm{CDCl}_{3}, \delta\right.$ in $\left.\mathrm{ppm}\right)$.

\begin{tabular}{lll}
\hline No. & $\delta_{H}$ (mult., $J[\mathrm{~Hz}]$, int. $)$ & $\delta_{c}$ \\
\hline 1 & $4.70(\mathrm{dd}, 6.1,11.5)$ & $66.2 \mathrm{~d}$ \\
3 & $3.74(\mathrm{dq}, 6.3,6.2)$ & $78.8 \mathrm{~d}$ \\
$3-\mathrm{CH}_{3}$ & $1.39(\mathrm{~d}, 6.2,3 \mathrm{H})$ & $21.6 \mathrm{q}$ \\
4 & $2.88(\mathrm{dq}, 6.3,6.9)$ & $38.1 \mathrm{~d}$ \\
$4-\mathrm{CH}_{3}$ & $1.23(\mathrm{~d}, 6.9,3 \mathrm{H})$ & $19.3 \mathrm{q}$ \\
\hline
\end{tabular}


Table 2. Cont.

\begin{tabular}{lll}
\hline No. & $\delta_{H}$ (mult., $J[\mathrm{~Hz}]$, int. $)$ & $\delta_{c}$ \\
\hline $4 \mathrm{a}$ & - & $145.8 \mathrm{~s}$ \\
5 & - & $118.2 \mathrm{~s}$ \\
$5-\mathrm{CH}_{3}$ & $2.14(\mathrm{~s}, 3 \mathrm{H})$ & $11.1 \mathrm{q}$ \\
6 & - & $161.3 \mathrm{~s}$ \\
$6 \mathrm{OH}$ & $12.16(\mathrm{~s})$ & - \\
7 & - & $97.6 \mathrm{~s}$ \\
$7-\mathrm{COOH}$ & - & $171.6 \mathrm{~s}$ \\
8 & - & $146.9 \mathrm{~s}$ \\
$8 \mathrm{a}$ & - & $111.7 \mathrm{~s}$ \\
10 & - & $101.4 \mathrm{~s}$ \\
$10-\mathrm{CH}_{3}$ & $1.87(\mathrm{~s}, 3 \mathrm{H})$ & $29.3 \mathrm{q}$ \\
$11 \mathrm{a}$ & $2.53(\mathrm{dd}, 6.1,12.8)$ & $37.3 \mathrm{t}$ \\
$11 \mathrm{~b}$ & $1.84(\mathrm{dd}, 11.5,12.8)$ & \\
\hline
\end{tabular}

Citrinolactone D (4) was obtained as a white, amorphous powder. $[\alpha]_{D}^{25}+6.7(0.004, \mathrm{MeOH})$. The molecular formula of 4 was determined as $\mathrm{C}_{14} \mathrm{H}_{14} \mathrm{O}_{4}$ by HRESIMS at $\mathrm{m} / z 269.07804[\mathrm{M}+\mathrm{Na}]^{+}$(calcd. 269.0790). The ${ }^{1} \mathrm{H}-\mathrm{NMR}$ data of 4 showed one aromatic methyl signal, one methoxyl group, two sp ${ }^{3}$ methylene signals, two aromatic protons, one oxygenated $\mathrm{sp}^{3}$ methine proton, and one hydroxyl proton (Table 3). The ${ }^{13} \mathrm{C}$-NMR spectrum of 4 displayed signals for two methyls (one of them oxygenated), two $\mathrm{sp}^{3}$ methylenes, one oxygenated $\mathrm{sp}^{3}$ methine, two $\mathrm{sp}^{2}$ methines, one carbonyl carbon, and $6 \mathrm{sp}^{2}$ quaternary carbons (Table 3). The NMR data were quite similar to those of 7 [5]. By comparison with those of 7, the NMR spectra of 4 exhibited an additional methoxyl group $\left(\delta_{H} 3.50, \delta_{c} 57.3\right)$ attached C-9, and which was further supported by $\mathrm{HMBC}$ correlations from 9- $\mathrm{OCH}_{3}$ to C-9 (Figure 2).

Table 3. The NMR data of compound $4\left(\mathrm{CDCl}_{3}, \delta\right.$ in ppm).

\begin{tabular}{lll}
\hline No. & $\delta_{H}$ (mult., J [Hz], int.) & $\delta_{c}$ \\
\hline 1 & - & $181.1 \mathrm{~s}$ \\
3 & - & $173.9 \mathrm{~s}$ \\
4 & - & $119.9 \mathrm{~s}$ \\
$4 \mathrm{a}$ & - & $157.3 \mathrm{~s}$ \\
5 & $6.71(\mathrm{~s})$ & $107.6 \mathrm{~d}$ \\
6 & - & $146.7 \mathrm{~s}$ \\
7 & $6.63(\mathrm{~s})$ & $112.6 \mathrm{~d}$ \\
8 & - & $161.0 \mathrm{~s}$ \\
$8-\mathrm{OH}$ & $12.56(\mathrm{~s})$ & - \\
$8 \mathrm{a}$ & - & $109.0 \mathrm{~s}$ \\
9 & $4.95(\mathrm{~d}, 6.8)$ & $79.4 \mathrm{~d}$ \\
$10 \mathrm{a}$ & $2.35(\mathrm{~m})$ & $27.6 \mathrm{t}$ \\
$10 \mathrm{~b}$ & $2.17(\mathrm{~m})$ & \\
$11 \mathrm{a}$ & $3.22(\mathrm{~m})$ & $30.2 \mathrm{t}$ \\
$11 \mathrm{~b}$ & $2.81(\mathrm{~m})$ & \\
12 & $2.40(\mathrm{~s}, 3 \mathrm{H})$ & $22.3 \mathrm{q}$ \\
$9-\mathrm{OCH}_{3}$ & $3.50(\mathrm{~s}, 3 \mathrm{H})$ & $57.3 \mathrm{q}$ \\
\hline
\end{tabular}




\subsection{Biosynthesis}

These compounds likely have the same biogenetic origin via the polyketide pathway [9]. citrinolactone B (7), citrinin (8), 2,3,4-trimethyl-5,7-dihydroxy-2,3-dihydrobenzofuran (9), phenol A (10) are biosynthesized from acetyl coenzyme A. Citrinolactone D (4) is the result of the methylation of citrinolactone B at 9-OH (7). To explain the biogenetic origin of penicitrinone E (1), penicitrinol J (2) and penicitrinol K (3), a postulated biosynthetic pathway is proposed in Schemes 1,2. Penicitrinone $\mathrm{E}$ (1) is postulated to derive from the oxidation of penicitrinol $\mathbf{J}(\mathbf{2})$, which results from the Diels-Alder reaction of 8 with 9 and then undergoes dehydration. Subsequent decarboxylation and the following dehydrogenation of penicitrinol J (2), leads successively to penicitrinone A (5) and penicitrinone B (6) [10] (Scheme 1). Oxidation of citrinin (8) forms dihydrocitrinone [11]. After undergoing aldol condensation of the carbonyl group at $\mathrm{C}-1$ of dihydrocitrinone with an acetone anion, which is biosynthesized from pyruvic acid via enzymatic reduction [12], dihydrocitrinone changes to an intermediate structure. Further dehydration, reduction and the following aldol condensation of the intermediate structure yields penicitrinol K (3) (Scheme 2). Based on this biosynthetic scheme, the absolute configurations were deduced as $3 R, 4 S, 2^{\prime} R, 3^{\prime} S$ - for $\mathbf{1}, 1 R, 3 R, 4 S, 2^{\prime} R, 3^{\prime} S$ - for $\mathbf{2}, 1 S, 3 R, 4 S$, $10 S$ - for $\mathbf{3}, 9 S$ - for 4.

Scheme 1. Postulated Biosynthesis of 1, 2,5 and 6 resulting from 8 and 9.

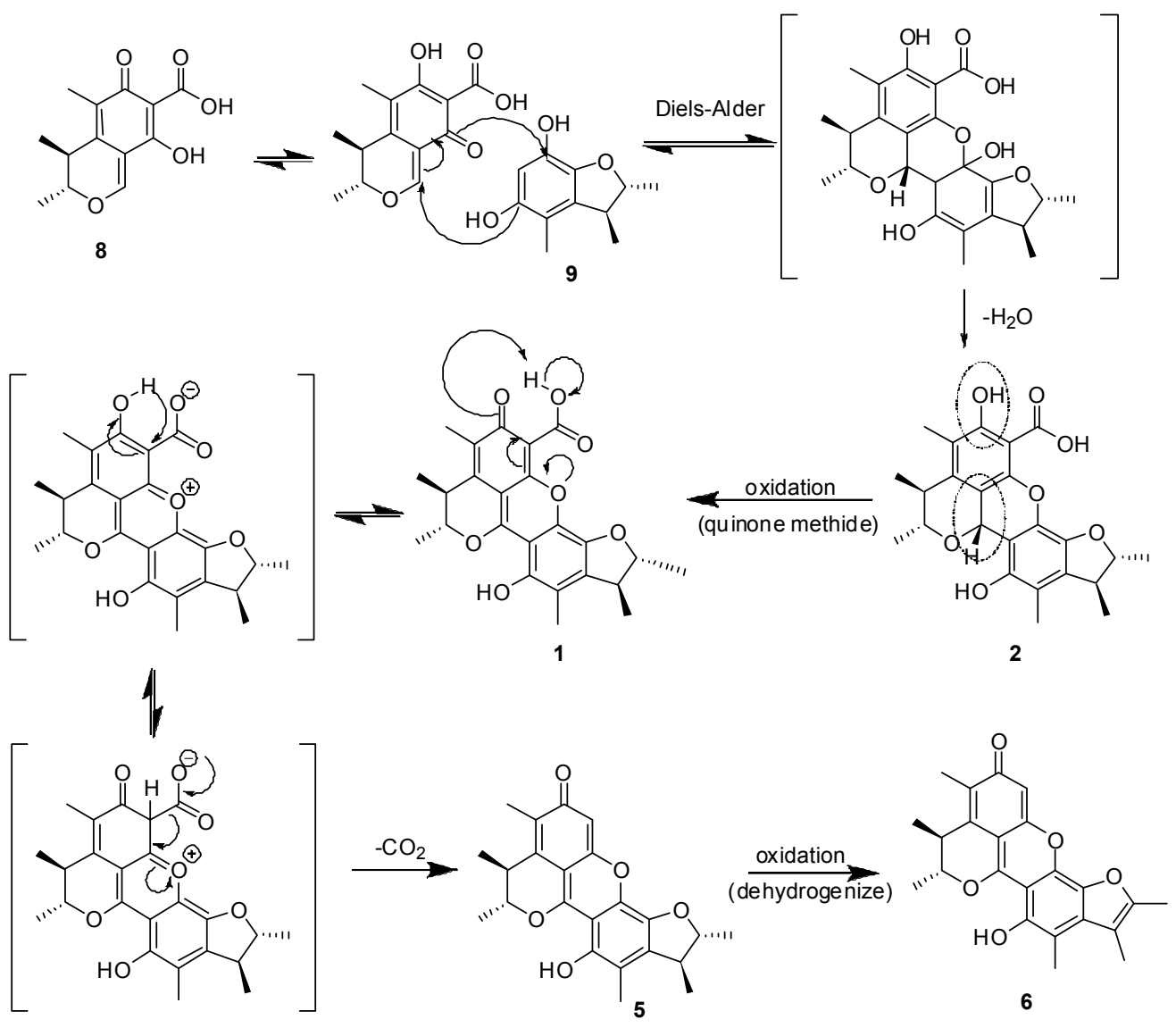


Scheme 2. Postulated Biosynthetic Pathway of 3.

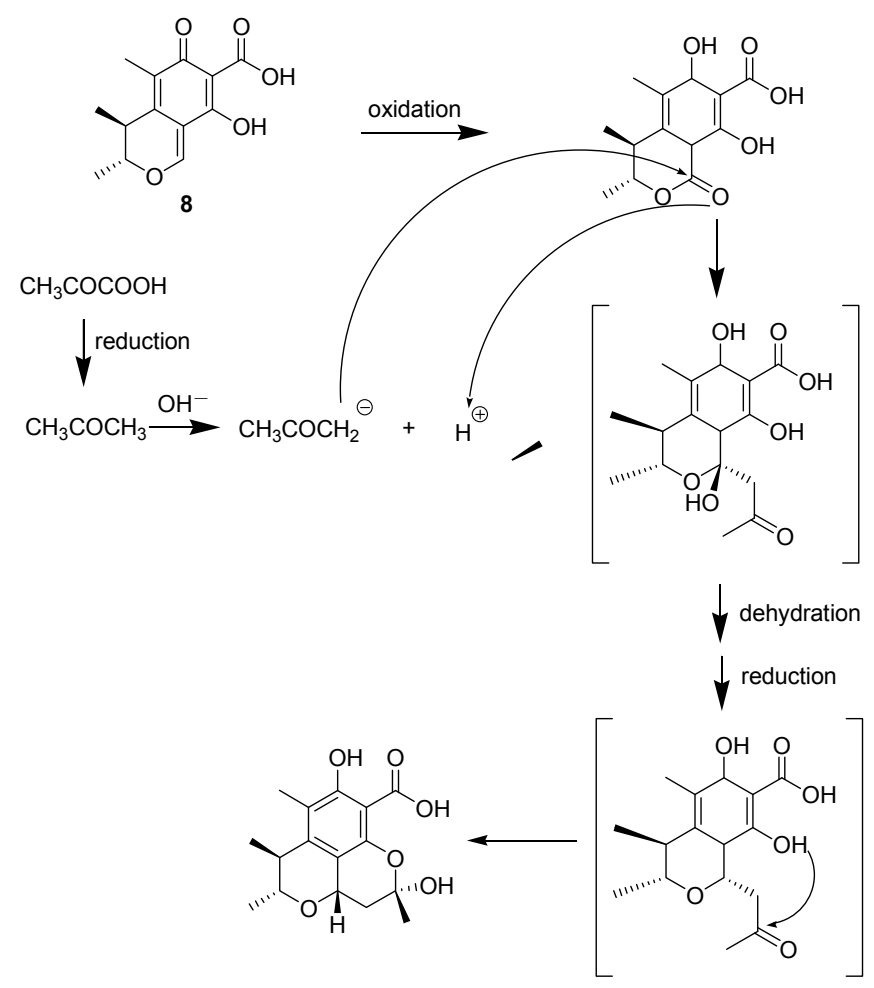

To best of our knowledge, four penicitrinones have been reported: penicitrinones A-B [4], pennicitrinone $\mathrm{C}$ [9] and pennicitrinone $\mathrm{D}$ [13] and nine penicitrinols have been reported: Penicitrinol A [4], pennicitrinol B [9], penicitrinols C-E [12] and penicitrinols F-I [14]; Three citrinolactones have been reported: citrinolactones $\mathrm{A}-\mathrm{C}[5]$. Thus, the four new citrinin derivatives-penicitrinone $\mathrm{E}$ (1), penicitrinol J (2), penicitrinol K (3) and citrinolactone D (4) enrich the number of penicitrinones, penicitrinols and citrinolactones respectively. Markedly, the 7-COOH of penicitrinone E (1) and penicitrinol J-K (2-3) were reported in both penicitrinones and penicitrinols for the first time, which complemented the Diels-Alder reaction of citrinin $[10,12]$.

\subsection{Cytotoxic and Antimicrobial Activity}

The new compounds 1-4 were tested for cytotoxic effects against the HeLa and HepG-2 cell lines using the MTT method [15]. However, they exhibited no remarkable cytotoxic activity against any of the cell lines in the concentration of $10 \mu \mathrm{g} / \mathrm{mL}$ (100\% of cis-platinum as positive control). The results of cytotoxic tests of compounds $\mathbf{1} \mathbf{- 4}$ are shown in Table 4 .

Table 4. Biological Activities of Compounds 1-4.

\begin{tabular}{ccc}
\hline \multirow{2}{*}{ Compound } & \multicolumn{2}{c}{ Inhibitory ratio (\%) } \\
\cline { 2 - 3 } & HeLa & HepG-2 \\
\hline $\mathbf{1}$ & - & 6.3 \\
$\mathbf{2}$ & - & 25.1 \\
$\mathbf{3}$ & - & 9.2 \\
$\mathbf{4}$ & 4.0 & 16.1 \\
\hline
\end{tabular}


The antimicrobial activity of compounds 1-4 against Staphylococcus aureus (CMCC26003), Escherichia coli (CMCC44103), Candida albicans (AS2.538), and Aspergillus niger (ACCC30005) were also evaluated by paper diffusion method with concentration of $20 \mu \mathrm{g} / 6 \mathrm{~mm}$ paper disk. Only compounds $\mathbf{2}$ and $\mathbf{3}$ showed weak antimicrobial activity against Staphylococcus aureus CMCC26003 with inhibition zones of 10 and $9 \mathrm{~mm}$ diameter, respectively (18 $\mathrm{mm}$ of gentamicin as positive control).

\section{Experimental}

\subsection{General Procedures}

Optical rotations were obtained on a PerkinElmer 341 automatic polarimeter. UV spectra were recorded on a Persee TU-1901 spectrophotometer. IR spectra were recorded on a Nicolet Avatar 330FT spectrometer. ${ }^{1} \mathrm{H}-\mathrm{NMR},{ }^{13} \mathrm{C}-\mathrm{NMR}$, and DEPT spectra and 2D NMR spectra were recorded on a Bruker Avance III-600 NMR spectrometer using TMS as internal standard, and chemical shifts were recorded as values. HRESIMS data were measured on a Bruker FT-ICR-MS mass spectrometer. ESIMS was measured on a Finnigan mass spectrometer. TLC was carried out using glass-precoated silica gel $\mathrm{GF}_{254}$ (Qingdao Marine Chemical, Inc., Qingdao, China) and visualized under UV light or by spraying with vanillin (contains $\mathrm{H}_{2} \mathrm{SO}_{4}$ ) ethanol reagent. Sephadex LH-20 (40-70 $\mu \mathrm{m}$, Amersham Pharmacia Biotech AB, Uppsala, Sweden), silica gel (200-300mesh, Qingdao Marine Chemical, Inc., Qingdao, China), and Lichroprep reversed-phase RP-18 silica gel (40-63 $\mu \mathrm{m}$, Merck, Darmstadt, Germany) were used for column chromatography (CC).

\subsection{Fungal Material}

The fungal strain Penicillium sp. ML226 was isolated from the sediment of Fu Gong mangrove region, Long Hai, Taiwan Strait, China. It was identified according to its morphological characteristics and ITS sequence. It was identified as a sporulating fungus by traditional morphology. A BLAST search result showed that the internal transcribed spaces (ITS) sequence of ML226 was highly homologous (96\% percent similarity) to that of a Penicillium species (JX192960), indicating that ML226 belongs to this genus. The voucher specimen is deposited in our laboratory at $-80{ }^{\circ} \mathrm{C}$. The producing strain was prepared on potato dextrose agar slants and stored at $4{ }^{\circ} \mathrm{C}$.

\subsection{Fermentation and Extraction}

The fungus Penicillium sp. ML226 was inoculated on slope of YMG media (glucose 4.0, malt extract 10.0, yeast extract 4.0, $\mathrm{pH} 7.2$ ) in a $250 \mathrm{~mL}$ solanad type flask containing solid media ( $25 \mathrm{~mL} /$ flask) at $28{ }^{\circ} \mathrm{C}$ for 4 days to afford spores. Then the spores were obtained by scraping and

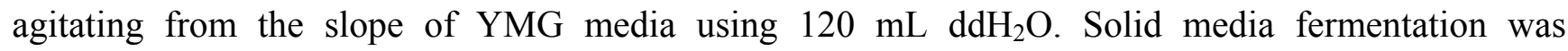
performed with YMG media $(12 \mathrm{~L})$ at $28^{\circ} \mathrm{C}$ for 7 days, and the spores was inoculated with inoculating loop. The cultured agar was chopped, diced and extracted with EtOAc-MeOH-AcOH (80:15:5, 3.5 liters) at room temperature overnight. The organic solution was collected through filtration, and the remaining agar residue was extracted several times more as described above until the filtrate was colourless. The combined filtrates were concentrated under vacuum to remove organic solvents. The aqueous solution was extracted five times with EtOAc to give an EtOAc solution, which was 
concentrated under vacuum to give a crude EtOAc extract. Then the EtOAc extract was dissolved with $\mathrm{MeOH}$ to give a $\mathrm{MeOH}$ solution. The $\mathrm{MeOH}$ solution was concentrated under vacuum to give a crude extract $(5.00 \mathrm{~g})$.

\subsection{Purification}

The crude $\mathrm{MeOH}$ extract (5.00 g) was subjected to MPLC over RP-18 silica gel (170 g) using a stepwise gradient of 30, 50, 70 and $100 \%(\mathrm{v} / \mathrm{v}) \mathrm{MeOH}$ in $\mathrm{H}_{2} \mathrm{O}$. Then we achieved Fr.B (244 mg) and Fr.C (251 mg) obtained from 30\% MeOH and Fr.D (560 mg) and Fr.E (362 mg) obtained from 50\% $\mathrm{MeOH}$. These fractions were further purified by repeated column chromatography $(\mathrm{CC})$ on Sephadex LH-20 and silica gel.

Fr.B (244 mg) was fractionated by Sephadex LH-20 CC (140 g, eluted with MeOH) to provide five fractions $(\mathrm{Ba}-\mathrm{Be})$. Fr.Bb $(50.9 \mathrm{mg})$ was fractionated by Sephadex LH-20 CC (80 g, eluted with acetone) to provide four fractions $(\mathrm{Bb} 1-\mathrm{Bb} 4)$. Fr.Bb2 $(8.0 \mathrm{mg})$ was further purified by silica gel $\mathrm{CC}$ [step gradient, 0-3\% EtOAc in petroleum ether (PE)] to yield 9 (3.4 mg). Fr.Bb4 (3.5 mg) was further purified by silica gel CC (step gradient, $0-10 \%$ EtOAc in PE) to afford $10(1.8 \mathrm{mg})$.

Fr.C (251 mg) was fractionated by Sephadex LH-20 CC (140 g, eluted with $\mathrm{MeOH})$ to provide seven fractions $(\mathrm{Ca}-\mathrm{Cg})$. Fr. $\mathrm{Cb}(36.6 \mathrm{mg})$ was further purified by silica gel CC (step gradient, $0-12.5 \%$ acetone in PE) to yield $\mathbf{1}(8.5 \mathrm{mg})$. Fr.Cd $(60.0 \mathrm{mg})$ was fractionated by Sephadex LH-20 CC (80 g, eluted with acetone) to provide four fractions (Cd1-Cd4). Fr.Cd2 (10.0 mg) was further purified by silica gel CC (step gradient, $0-2.5 \%$ acetone in PE) to obtain 9 (3.2 mg). Fr.Cg (34, $2 \mathrm{mg})$ was further purified by silica gel CC (step gradient, $0-1.5 \%$ EtOAc in PE with $0.5 \% \mathrm{HCOOH}$ ) to produce 2 (4.0 $\mathrm{mg})$ and $1(2.2 \mathrm{mg})$.

After settling, some crystals of $8(80.7 \mathrm{mg})$ appeared in Fr.D $(560 \mathrm{mg})$ and the remaining mother liquor solution (463 mg) was fractionated by Sephadex LH-20 CC (140 g, eluted with MeOH) to provide seven fractions (Da-Dg). Fr.Dc $(73.6 \mathrm{mg}$ ) was fractionated by Sephadex LH-20 CC [80 g, eluated with MeOH/acetone (1:4)] to provide four fractions (Dc1-Dc4). Fr.Dc3 (26.0 mg) was further purified by silica gel CC (step gradient, 0-50\% EtOAc in PE) to yield 6 (3.7 mg).

Fr.E (362 mg) was fractionated by Sephadex LH-20 CC (140g, eluted with MeOH) to provide five fractions (Ec-Ee). Fr.Ec (55.1 mg) was fractionated by Sephadex LH-20 CC [80 g, eluted with MeOH/ acetone (1:4)] to provide three fractions (Ec1-Ec3). Fr.Ec2 $(24.0 \mathrm{mg})$ was further purified by silica gel CC (step gradient, 0-25\% acetone in PE) to yield 5 (3.0 mg). Fr.Ee (121.9 mg) was fractionated by Sephadex LH-20 CC (140g, eluted with acetone) to provide four fractions (Ee1-Ee4). Fr.Ee2 (12.9 $\mathrm{mg}$ ) was further purified by silica gel CC (step gradient, 0-2.5\% acetone in PE) to yield 3 (3.2 $\mathrm{mg}$ ). Fr.Ee3 (43.0 mg) was further purified by silica gel CC (step gradient, 0-3.3\% acetone in PE) to yield 4 (7.1 mg). Fr.Ee4 (73.0 mg) was fractionated by Sephadex LH-20 CC [80 g, eluted with MeOH/ acetone (1:4)] to provide three fractions ((Ee41-Ee43). Fr.Ee43 (36.9 mg) was further purified by silica gel CC (step gradient, 0-3.3\% acetone in PE) to obtain 7 (2.6 mg). 


\subsection{Biological Assays}

Cancer cell lines were derived from the cell bank of the Chinese Academy of Sciences. The cytotoxicities of the compounds 1-5 were measured by the MTT (Sigma) assay [15]. The cells in 100 $\mu \mathrm{L}$ of culture medium were plated in each well of 96-well plates (Falcon, CA). After $24 \mathrm{~h}$ of incubation for a density of $5 \times 10^{3} / 100 \mu \mathrm{L}$ medium, the cells were treated in triplicate with the concentration of $10 \mu \mathrm{g} / \mathrm{mL}$ of every compound for $72 \mathrm{~h}$ at $37{ }^{\circ} \mathrm{C}$. A $20 \mu \mathrm{L}$ aliquot of MTT solution $(5 \mathrm{mg} / \mathrm{mL})$ was added directly to all wells and incubated for $4 \mathrm{~h}$ at $37{ }^{\circ} \mathrm{C}$. To quench the reaction, 100 $\mu \mathrm{L}$ of triplex solution (10\% SDS, $5 \%$ isobutanol, $12 \mathrm{mM} \mathrm{HCl}$ ) was added to each well and incubated overnight at $37{ }^{\circ} \mathrm{C}$. The optical density of each well was measured with a microplate reader (M-3350, Bio-Rad) at $595 \mathrm{~nm}$ (excitation). Growth inhibition rates were calculated with the following equation:

$$
\text { Inhibition } \quad \text { rate }=\frac{O D_{\text {control }}-O D_{\text {treated }}}{O D_{\text {control }}-O D_{\text {blank }}} \times 100 \%
$$

\subsection{Spectral Data}

Penicitrinone E (1): red, amorphous powder; $[\alpha]_{D}^{25} 0(0.002, \mathrm{MeOH})$; UV (MeOH) $\lambda_{\max }(\log \varepsilon) 204$ (2.74), 214 (2.76), 232 (2.58), 258 (2.37), 278 (2.49), 315 (2.34), 400 (2.49) nm; IR (KBr) $v_{\max } 3453$, 2967, 2928, 2873, 2358, 2332, 1687, 1641, 1611, 1527, 1506, 1451, 1408, 1380, 1325, 1269, 1154, 1101, 1060, 1026, 993, 933, 899, 858, 822, 748, 700, 675, 652, 552, $505 \mathrm{~cm}^{-1} ; R_{\mathrm{f}}=0.318(\mathrm{PE}:$ acetone $=1: 1), R_{\mathrm{f}}=0.611\left(\mathrm{PE}:\right.$ acetone $=1: 1$, with formic acid); ${ }^{1} \mathrm{H}-$ and ${ }^{13} \mathrm{C}-\mathrm{NMR}$ (see Table 1$)$; HRESIMS $m / z 425.15965[\mathrm{M}+\mathrm{H}]^{+}$(calcd. for $\mathrm{C}_{24} \mathrm{H}_{25} \mathrm{O}_{7}, 425.1600$ ).

Penicitrinol J (2): pale yellow, amorphous powder; $[\alpha]_{D}^{25}-30.0(0.001, \mathrm{MeOH}) ; \mathrm{UV}(\mathrm{MeOH}) \lambda_{\max }(\log$ ع) 203 (3.05), 215 (3.12), 257 (2.61), 277 (2.56), 315 (2.55), 400 (2.51) nm; IR (KBr) v $v_{\max }$ 3343, 2967, 2925, 2869, 2364, 2338, 1684, 1636, 1586, 1527, 1504, 1451, 1421, 1385, 1328, 1274, 1239, 1165, 1136, 1074, 1022, 996, 974, 929, 907, 858, 815, 778, 754, 729, 704, 636, $550 \mathrm{~cm}^{-1} ; R_{\mathrm{f}}=0.591(\mathrm{PE}:$ acetone $=1: 1), R_{\mathrm{f}}=1\left(\mathrm{PE}\right.$ :acetone $=1: 1$, with formic acid); ${ }^{1} \mathrm{H}$ - and ${ }^{13} \mathrm{C}-\mathrm{NMR}$ (see Table 1$)$; HRESIMS $m / z$ 427.17601 [M + H $]^{+}$(calcd. for $\mathrm{C}_{24} \mathrm{H}_{27} \mathrm{O}_{7}, 427.1757$ ).

Penicitrinol K (3): white, amorphous powder; $[\alpha]_{D}^{25}-125.2(0.002, \mathrm{MeOH}) ; \mathrm{UV}(\mathrm{MeOH}) \lambda_{\max }(\log \varepsilon)$ 213(2.68), 257 (2.34), 325 (1.90) nm; IR (KBr) v $v_{\max }$ 3433, 3230, 2970, 2930, 2872, 2360, 2334, 1687, 1623, 1589, 1445, 1419, 1386, 1353, 1298, 1270, 1232, 1200, 1169, 1105, 1079, 1025, 905, 876, 809, 753, 729, 683, 582, $549 \mathrm{~cm}^{-1} ; R_{\mathrm{f}}=0.524\left(\mathrm{CHCl}_{3}: \mathrm{MeOH}=10: 1\right) ;{ }^{1} \mathrm{H}-$ and ${ }^{13} \mathrm{C}-\mathrm{NMR}$ (see Table 2); The citrinin moiety's HRESIMS $m / z 273.07299[\mathrm{M}+\mathrm{Na}]^{+}$(calcd. for $\mathrm{C}_{13} \mathrm{H}_{14} \mathrm{O}_{5} \mathrm{Na}, 273.0739$ ); ESIMS $m / z 331.2[\mathrm{M}+\mathrm{Na}]^{+}$and $291.4\left[\mathrm{M}-\mathrm{H}_{2} \mathrm{O}+\mathrm{H}\right]^{+}$.

Citrinolactone D (4): white, amorphous powder; $[\alpha]_{D}^{25}+6.7(0.004, \mathrm{MeOH}) ; \mathrm{UV}(\mathrm{MeOH}) \lambda_{\max }(\log \varepsilon)$ 204 (2.35), 229 (2.45), 237 (2.49), 257 (2.31), 325 (1.80) nm; IR (KBr) v $v_{\max }$ 3437, 2965, 2924, 2824, 2365, 2337, 1653, 1622, 1599, 1490, 1451, 1364, 1296, 1253, 1206, 1141, 1083, 1031, 1011, 941, 922, $869,822,784,757,698,656,619,570,513,471 \mathrm{~cm}^{-1} ; R_{\mathrm{f}}=0.675(\mathrm{PE}:$ acetone $=2: 1) ;{ }^{1} \mathrm{H}-$ and ${ }^{13} \mathrm{C}-\mathrm{NMR}$ (see Table 3); HRESIMS $m / z 269.07804[\mathrm{M}+\mathrm{Na}]^{+}$(calcd. for $\mathrm{C}_{14} \mathrm{H}_{14} \mathrm{O}_{4} \mathrm{Na}, 269.0790$ ). 


\section{Conclusions}

Four new compounds, penicitrinone E (1), penicitrinol J (2), penicitrinol K (3) and citrinolactone D (4), were isolated together with six known compounds from the marine-derived Penicillium sp. ML226. Penicitrinone E (1), penicitrinol J (2) and penicitrinol K (3) showed modest selective cytotoxixity against HepG-2 cell line. Citrinolactone D (4) showed weak cytotoxixity against HepG-2 and HeLa cell lines. penicitrinol J (2) and penicitrinol K (3) showed mild antimicrobial activity against Staphylococcus aureus.

\section{Supplementary Materials}

The NMR spectra and HRESIMS spectra of compounds $\mathbf{1}-\mathbf{4}$ can be accessed at: http://www.mdpi.com/1420-3049/18/5/5723/s1.

\section{Acknowledgments}

This work was financially supported by the "863" project (2006AA09Z410, 2007AA091503) of the Ministry of Science and Technology and the Fundamental Research Funds for the Central Universities (No.2011121037).

\section{Conflict of Interest}

The authors declare no conflict of interest.

\section{References}

1. Tamburini, E.; Mastromei, G. Do bacterial cryptic genes really exist? Res. Microbiol. 2000, 151, 179-182.

2. Liberra, K.; Lindequist, U. Marine fungi-A prolific resource of biologically active natural products? Pharmazie 1995, 50, 583-588.

3. Bugni, T.S.; Ireland, C.M. Marine-derived fungi: a chemically and biologically diverse group of microorganisms. Nat. Prod. Rep. 2004, 21, 143-163.

4. Wakana, D.; Hosoe, T.; Itabashi, T.; Okada, K.; Takaki, G.M.D.; Yaguchi, T.; Fukushima, K.; Kawai, K. New citrinin derivatives isolated from Penicillium citrinum. J. Nat. Med. 2006, 60, 279-284.

5. Kuramata, M.; Fujioka, S.; Shimada, A.; Kawano, T.; Kimura, Y. Citrinolactones A, B and C, and Sclerotinin C, plant growth regulators from Penicillium citrinum. Biosci. Biotechnol. Biochem. 2007, 71, 499-503.

6. Hetherington, A.C.; Raistrick, H. Studies in the biochemistry of microorganisms. XI. On the production and chemical constitution of a new yellow coloring matter, citrinin, produced from glucose by Penicillium citrinum THOM. Philos. Trans. R. Soc. London Ser. B 1931, 220, 226-297.

7. Chen, C.H.; Shaw, C.Y.; Chen, C.C.; Tsai, Y.C. 2,3,4-Trimethyl-5,7-dihydroxy-2,3dihydrobenzofuran, a novel antioxidant, from Penicillium citrinum F5. J. Nat. Prod. 2002, 65, 740-741. 
8. Rodel, T.; Gerlach, H. Enantioselective Synthesis of the Polyketide Antibiotic (3R,4S)-(-)Citrinin. Liebigs Ann. 1995, 1995, 885-888.

9. Lu, Z.Y.; Lin, Z.J.; Wang, W.L.; Du, L.; Zhu, T.J.; Fang, Y.C.; Gu, Q.Q.; Zhu, W.M. Citrinin dimers from the halotolerant fungus Penicillium citrinum B-57. J. Nat. Prod. 2008, 71, 543-546.

10. Clark, B.R.; Capon, R.J.; Lacey, E.; Tennant, S.; Gill, J.H. Citrinin revisited: from monomers to dimers and beyond. Org. Biomol. Chem. 2006, 4, 1520-1528.

11. Chien, M.M.; Schiff, P.L., Jr.; Slatkin, D.J.; Knapp, J.E. Metabolites of aspergilli. III. The isolation of citrinin, dihydrocitrinone and sclerin from aspergilus carneus. Lloydia 1977, 40, 301-302.

12. Chen, L.; Liu, W.; Hu, X.; Huang, K.; Wu, J.L.; Zhang, Q.Q. Citrinin derivatives from the marine-derived fungus Penicillium citrinum. Chem. Pharm. Bull. (Tokyo) 2011, 59, 515-517.

13. Xin, Z.H.; Wang, W.L.; Zhang, Y.P.; Xie, H.; Gu, Q.Q.; Zhu, W.M. Pennicitrinone D, a new citrinin dimer from the halotolerant fungus Penicillium notatum B-52. J. Antibiot. (Tokyo) 2009, 62, 225-227.

14. Chen, L.; Liu, W.; Huang, K.; Hu, X.; Fang, Z.X.; Wu, J.L.; Zhang, Q.Q. Penicitrinols F-I, New Citrinin Derivatives from the Marine-Derived Fungus Penicillium citrinum. Heterocycles 2011, 83, 1853-1858.

15. E, Z. Tissue Culture And Molecular Biology Technology; Beijing Publishing House: Beijing, China 1995; pp. 1-141.

Sample Availability: Samples of the compounds 1-10 are available from the authors.

(C) 2013 by the authors; licensee MDPI, Basel, Switzerland. This article is an open access article distributed under the terms and conditions of the Creative Commons Attribution license (http://creativecommons.org/licenses/by/3.0/). 